\title{
Data Analytics and Cloud Computing vs Breast Cancer: Learning That Helps
}

\author{
Mónica Larre-Bolaños-Cacho, Sergio Hernández-Alamilla, Ramona Fuentes-Valdéz, Pedro \\ Najera-García
}

\begin{abstract}
This article presents the deployment of the Semester i (i-Sem) "Data Analytics and Cloud Computing vs Breast Cancer: learning that helps" $(D A \& C C v s B C)$.

i-Sem is one of the elements of the Tec21 educational model of The Monterrey Tech. $D A \& C C v s B C$ is a learning environment where engineering students developed competences, by resolving an inspiring challenge designed from a problem posed by a training partner $(T P)$. The challenge consisted in designing and implementing computer applications to support the follow-up of patients with breast cancer before and during their treatment.

The project started with the selection of a list of competences to be developed in the students. From that list and based on a real problem situation posed by two training partners (TPs), a challenge was designed. The challenge was presented to students interested in participating and 11 students were selected. So, in 18 weeks, the students, accompanied by professors, built solution proposals for the challenge. During the construction process, the students developed the established competences. The project had a vision: "learning that helps".

The intended outcomes were: A report that evidenced the development of students' competences, and two computer applications for monitoring the treatment of patients with breast cancer.
\end{abstract}

Index Terms - Educational innovation and higher education, competency-based learning, computer sciences, learning environment, computer applications, breast cancer, data analytics, cloud computing.

\section{INTRODUCTION}

THE Monterrey Tech [1] (The Tec) is a private university in Mexico, founded in 1943 and currently with a presence in more than 20 cities in the country. Being congruence with its vision ("Leadership, innovation and entrepreneurship for human flourishing") and its purpose ("life-transforming training"), the institution made the decision to transform its educational model to adapt it to the new world trends, taking into account the new student profiles, the new demands of the labor market and the rise of information technologies at global level. The transformation of its academic model began in 2012 with consultations with graduates, professors, students and employers, and the process resulted in the so-called Tec21 Model [2]; the official launch to the academic community occurred in 2015 .

Manuscript received November 12, 2019; revised March 5, 2020

The authors are with the Computer Department, Tecnológico de Monterrey, México (e-mail: sergiohernandez@tec.mx).
The Tec21 Model proposes the formation of solid and integral egress competences by placing a challenge as a trigger for the learning process, where the student, when solving it, develops his potential to transform his present environment and trains himself for his professional future. The essence of the model [3] is shown in Fig. 1.

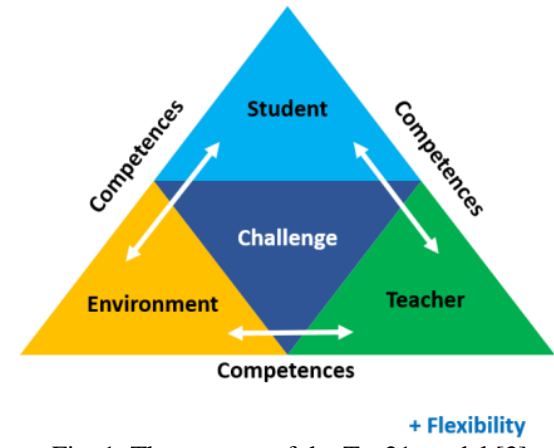

Fig. 1. The essence of the Tec21 model [3].

The i-Sem is one of the core initiatives of the Tec21 and incorporates, by design, all the model elements [3]. A challenge appears in the center and it is the detonator of competency-based learning. The student is the protagonist and has an active role. Professors act as Mentors and Advisors and the environment links the classroom with the outside world.

In this article, we present the project "Data Analytics and Cloud Computing vs Breast Cancer: Learning that Helps", $D A \& C C v s B C$ as a learning environment [4] for development of competences in computer sciences.

The structure of the article is as follows: Section II describes the origins of the project. Section III describes the four stages (4-S) of $D A \& C C v s B C$ design. Section IV details the Competency-based Learning Model used in $D A \& C C v s B C$. Section $\mathrm{V}$ presents the Architecture and outcomes of the deployment of $D A \& C C v s B C$; and finally, Section VI includes Conclusions, Findings and Future Work.

\section{ThE ORIGIN OF THE $D A \& C C V S B C$ PROJECT}

With the aim of bringing the Tec21 Model to the classrooms of The Tec in Campus Cuernavaca, and as a result of the research and bonding work of a group of teachers (called DT, Design Team), at the end of 2017, raised the idea to design an i-Sem with the vision: "learning that helps".

The project design concluded in January 2018, and it was accepted by the Academic Authorities of The Tec on February 2018 under the title of "Data Analytics and Cloud Computing vs Breast Cancer: Learning that Helps" to be implemented on the Cuernavaca Campus in the academic 
period of August-December 2018.

\section{A. The Dream Became a Challenge}

The first activity of the $D T$ consisted in selecting a list of competences to be developed. Then, we looked for training partners (TPS) interested in offering our students the opportunity of learning through to solve a problematic situation existing in their organizations (see e.g. [5]).

The TPs are fundamental members of the Tec21 Model. They are called training partners because they participate in the process of developing competences of students. They are the link between school and real life. They are not simple spectators who benefit from the products generated in the i-Sem, on the contrary, they are active members of the team that are involved in the whole process: they participate in the design phase of the challenge by presenting real problems that need to be solved, then, they become expert Advisors that feed the solution proposals in the deployment phase; and finally, they participate in the implementation of the solutions proposed by the students in their organizations.

Fortunately, two extraordinary training partners joined the project. The first $T P$ was Indra, a multinational consulting firm at its Mexico headquarters [6], [7]. A team of consultants promoted the integration of the required elements to initiate the i-Sem and linked the $D T$ with what would be the second and strategic $T P$.

The second $T P$ was the National Cancer Institute, INCan [8], a public health institution of the federal government that offers medical and hospital care to cancer patients throughout Mexico, many of them, patients without access to social security.

We were very interested in working with INCan because in Mexico, cancer presents itself as one of the major challenges in public health [9]. Malignant tumors have been positioned as one of the leading causes of mortality for several decades. The mortality projections for 2020 show that of the ten leading causes of cancer death, breast, prostate and liver cancer are constantly increasing every year, reaching rates of more than 5 deaths per 100 thousand people; and specifically, as mentioned in [10], breast cancer is predicted to exceed 11 cases per 100 thousand.

Against this background, the challenges that INCan currently faces are many, mostly due to the high demand for medical and hospital care. For this reason, the institution selected its Department of Mammary Tumors as the place to identify a problem situation that was the basis for designing a challenge that could be solved using information technologies [11].

Finally, using [12]-[15], and based on the selected competences, the DT and the INCan defined the challenge as "design and implement computer applications to support the follow-up of patients with breast cancer before and during their treatment". Because of the technology that we planned to use, the i-Sem was registered under the title of "Data Analytic and Cloud Computing vs Breast Cancer: Learning that Helps". Due to the environment and theme, the designed challenge would follow the original established vision "learning" (development of skills in students) "that helps" (using the profession to help others).

\section{THE STAGES OF DA\&CCVSBC}

The $D A \& C C v s B C$ project had a 4-Stages Model that occurred in a timeline. The model is shown in Fig. 2. The four stages constituted the lifetime of the project: Start, Design, Selection and Deployment. The project was designed as a Learning Environment built from an inspiring problem situation and focused on the development of skills.

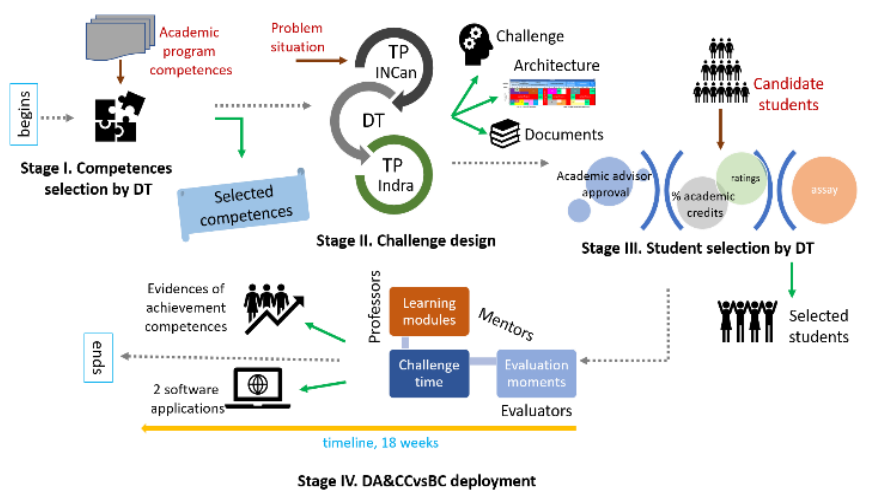

Fig. 2. The DA\&CCvsBC 4-stages model.

\section{A. The Teacher's Roles}

The teachers' roles proposed in the Tec21 Model are: Mentors, Professors and Evaluators [16] and for $D A \& C C v s B C$; one of the main tasks of the DT was the selection of the teachers who would participate in each of the project stages.

Two teachers were selected to participate as Mentors. Their main role was to provide personalized support and continuous formative feedback to the students [17], [18]. Also, Mentors participated in evaluation moments and were observers throughout the deployment stage.

For the role of Professor, six teachers were selected. All of them, experts in different Computer Science areas, with an extensive teaching experience and wide recognition within the institution. Their main activities were to develop and evaluate discipline skills. As the Mentors, some of the Professors were observers in great part of the deployment phase. Two teams of Advisors joined the group of Professors. One team advised and fed our students on computer science issues (three experts from Minsait by Indra), and the other team advised our students in medical matters (tree Oncologists from INCan). The Advisors also participated in the final Evaluation Moment.

Finally, the Evaluators role [19], [20] was to assess the progress of competences in each of the eleven students. Therefore, eight Evaluators were appointed for $D A \& C C v s B C$

\section{B. From the Design Stage to the Deployment Stage}

As shown in Fig. 2, in Stage I the DT selected the target competences. The product of this stage was the list of competences that would be developed by the students through the deployment of our project.

During Stage II, the problem situation was selected, and the challenge was designed. This stage was led by the $D T$, but both TPs also participated. Three products were the output of this stage: The statement of the challenge, the academic deployment model (the architecture) and the documentation 
required by the Tec21 Model regulations.

During Stage III, the DT selected the students who would participate in the project. The profile of the candidate students was established as being a student of the Tec, being enrolled in the BS Computer Science and Technology, having at least $60 \%$ of the program credits approved and having their Academic Advisor approval. In addition, each candidate who met the basic requirements should submit an essay describing their motivation to participate in the i-Sem. The outcome of this stage was a team of eleven students capable and eager to participate.

The duration of the last stage (Stage IV) was 18 weeks and consisted of the deployment of the $D A \& C C v s B C$ academic model. The products of this stage were: A report with the level of competence development observed in students and the software applications developed by students to solve the proposed challenge.

\section{The DeVElopment of COMPETENCES IN STUDENTS THROUGH DEPLOYMENT OF DA\&CCVSBC}

According to [21] and [22], the learning process of the competency-based model begins with the selection of the specific competences to be developed, and from them, design an inspiring challenge whose solution process leads the students to develop each of the chosen skills. Supported by Professors and Mentors, the students can reach the domain of the competences at their own pace, developing the skills they "feel" is necessary to achieve the solution of the challenge.

\section{A. The Competences of DA\&CCvsBC}

The selection of which and how many competences would be included in the project, was made based on the extensive academic and discipline experience of the $D T$.

$D T$ selected Area (discipline) Competences from the graduation profile of the academic program BS Computer Science and Technology of the Tec. In addition, in accordance to [23], Transversal Competences were included in $D A \& C C v s B C$. This set of competences is not exclusive to any of the academic programs and are considered important allies for the good performance of professionals in a globalized and multidisciplinary world [24]-[26].

On the other hand, in [27] is stated that for any competency-based learning model, the expected domain level to be achieved for each one of the competences must be determined. For our project, we selected a three levels of domain scheme: $A$ (basic), $B$ (intermediate) and $C$ (advanced). Due to the profile of the selected students, the expected levels of proficiency would be only $\mathrm{B}$ or $\mathrm{C}$.

Table 1 shows the domain levels for the $D A \& C C v s B C$ competences. Two computer science competences were selected, each one with two sub-competences. In all cases, the expected domain levels would be $B$ or $C$. In turn, three Transversal Competences were selected, one with two sub-competences and two with one sub-competence. Also, for the Transversal sub-Competences the expected domain level would be $\mathrm{B}$ or $\mathrm{C}$.

\section{B. Evaluation of the Training Process}

Competency-based learning requires an evaluation process for students [28]-[30] to check the progress of the development of their competences. At $D A \& C C v s B C$, each student built an evidence's e-Portfolio [31], [32] to demonstrate such progress. The e-Portfolio was very useful because it also allowed to observe, at an early stage, the knowledge and skills they still needed to reinforce.

Fig. 3 shows the Evaluation Moments of $D A \& C C v s B C$ in which each student placed evidence to be evaluated. In most cases, evidences were evaluated in a collegial way by the group of Evaluators.

TABLE I: THE $D A \& C C V S B C$ DISCIPLINE AND TRANSVERSE COMPETENCES, SUB-COMPETENCES AND THE EXPECTED DOMAIN LEVEL ${ }^{\mathrm{A}}$

\begin{tabular}{|c|c|c|c|c|}
\hline Competences & Sub-competences & $\begin{array}{c}\text { Domain } \\
\text { level }\end{array}$ & Discipline & Transversal \\
\hline \multirow{2}{*}{ D1 } & D11 & B & & \\
\hline & D12 & $\mathrm{C}$ & & \\
\hline \multirow{2}{*}{ D2 } & D21 & $\mathrm{C}$ & & \\
\hline & D22 & B & & \\
\hline $\mathrm{T} 1$ & $\mathrm{~T} 11$ & $\mathrm{C}$ & & \\
\hline \multirow{2}{*}{$\mathrm{T} 2$} & $\mathrm{~T} 21$ & $\mathrm{C}$ & & \\
\hline & $\mathrm{T} 22$ & B & & \\
\hline $\mathrm{T} 3$ & T31 & B & & \\
\hline
\end{tabular}

${ }^{\mathrm{a}}$ The Tec Academic Programs have 7 Transversal Competences defined in [16].

Because formative feedback is the element that gives the students the control of their learning [33], during the entire deployment of the project, students were exposed to oral and written feedback, with the aim of aligning efforts and actions in the development of their goal competences. That's why teachers, TPs, and students participated in formative feedback processes. An example of written formative feedback used in the project is presented in Fig. 4.

In summary, Fig. 5 shows the different moments in which each member of the evaluation team participated in the evaluation and feedback processes.

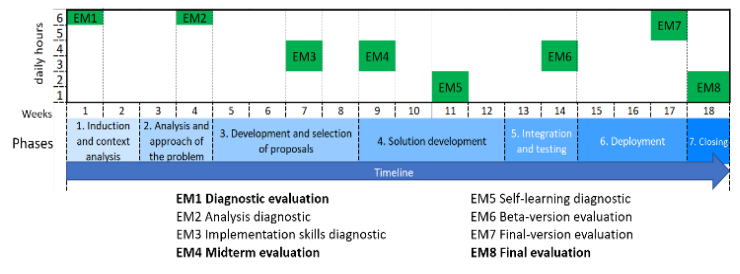

Fig. 3. The evaluation moments in $D A \& C C v s B C$.

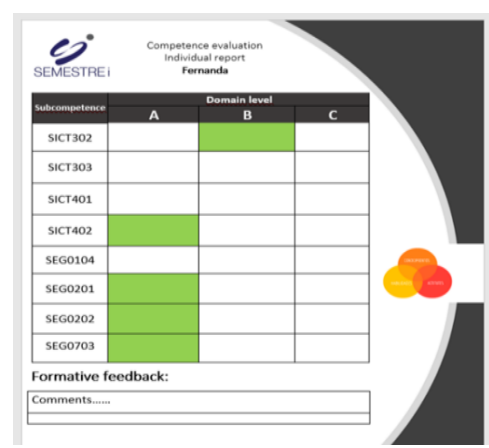

Fig. 4. Formative feedback formats used in $D A \& C C v s B C$. 


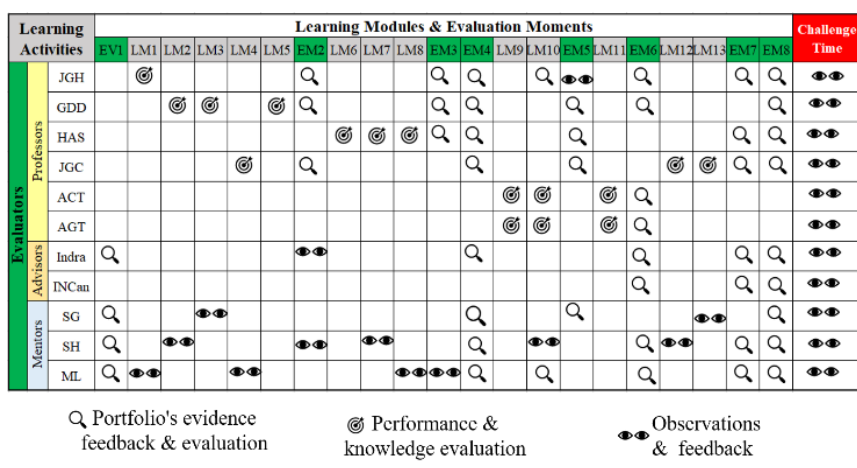

Fig. 5. The evaluation process during the $D A \& C C v s B C$ deployment.

\section{AN ARCHITECTURE FOR THE ACADEMIC DEPLOYMENT OF $D A \& C C V S B C$}

The architecture for the academic deployment of $D A \& C C v s B C$ included all the elements indicated in the Tec21 Model for an i-Sem. Our design was built from a set of flexible learning moments [4] that occurred over a period of eighteen weeks. The architecture combines different teaching techniques and didactic activities, as well as learning support tools for each moment (see e.g. [14], [34]).

\section{A. The Architecture}

The architecture for the deployment of $D A \& C C v s B C$ is shown in Fig. 6. The design was a specific one to develop Transversal and Discipline Competences in computer sciences students by solving the challenge posed.

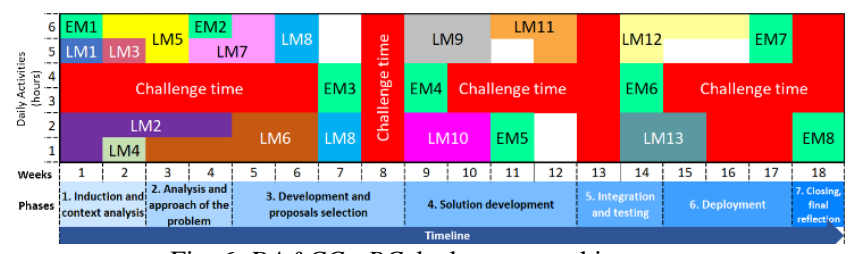

Fig. 6. $D A \& C C v s B C$ deployment architecture.

Our model included: thirteen Learning Modules ( $L M s)$, Challenge Time $(C T)$ and eight Evaluation Moments (EMs) distributed over time through seven implementation phases (IPs).

The IPs were consistent with the software development methodologies and gave the project a sequence in time in which the solution of the challenge was built.

During the $L M s$ (numbered from 1 to 13) students worked on computer science topics. The modules integrated different learning activities to develop the target competences and were led by the Professors. The sequence in time for each $L M$ was determined by the implementation phase to which it belonged. The sequence considered the opportune moment in which each topic had to be treated to provide knowledge and skills to the solution of the challenge.

On the other hand, the $C T$ consisted of a set of moments in which the students, through individual reflections and collaborative experiences, built the solution to the challenge.

Finally, the evaluation activities were distributed at strategic moments of the project deployment: The Evaluation Moments. The evaluation activities and tools applied were different, and they adapted to the topic and time in which they were presented.

\section{B. Model Focused on Learning}

Looking to preserve the motivation of the students and due to the modular architecture of our model, different teaching-and-learning activities and various tools [35] were selectively incorporated during the deployment of the project. In addition, the $D T$ decided to incorporate the use of technological tools (e.g. GitHub, Trello, Zoom, Blackboard, Google Drive, Google Calendar, Hangout, WhatsApp) to strengthen learning activities [13]. Most of these tools also contributed to improving communication among all participants throughout the project.

For $L M s$, the main teaching strategy chosen was the flipped classroom [36]-[39]. This strategy was used to transform students into partners in their learning process, in addition, to allow teachers to provide a more personalized and close attention to students.

The $C T$ was a set of moments in which the students put into practice what they learned, that's why for $C T$ we included the active learning strategy [40]-[42]. Working individually and collaboratively [43], [44], during $C T$, students designed and built the proposals to solve the challenge. They worked on their own and at their own pace. We observed that these moments were highly formative and those that most contributed to the training of discipline and transversal skills. In addition, because self-learning [45], [46] guide students to develop lifelong autonomous learning skills, we included in $C T$ some activities using Massive Open Online Courses (MOOCs) [47]. Selected MOOCs allowed students to learn specific topics on their own.

As mentioned before, depending on the topic and time, for EMs we used different activities and evaluation instruments [48]:

- Oral presentations and observations (EM4, EM8). Evaluated with observation guides.

- Technical reports (EM4, EM7, EM8). Evaluated with checklists.

- Interviews (EM1, EM6). Evaluated through questionnaires.

- Co-assessment activities (EM2, EM4, EM6, EM7). Attitude scales were used.

- Performance (EM2, EM3, EM5, EM6, EM7). Evaluated through written practical exams.

\section{Results of the Project Deployment}

The $D A \& C C v s B C$ deployment outputs were of two types:

- A document that included the final report with the level of proficiency achieved by each student in each of the declared competences.

- Two software products, developed by the students, that solved the challenge.

TABLE II: THE PROFICIENCY LEVEL ACHIEVED By THE STUDENTS

\begin{tabular}{|c|c|c|c|c|c|c|c|c|c|c|c|c|c|c|c|c|c|c|c|c|c|c|c|}
\hline thathe & & & Diagnosti & atic Evalh & athation & & & & & Midt & term Ev & atiti & & & & & & & nal Eva & aluation & & & \\
\hline tonatiol & B & c & B & c & c & B & B & B & c & c & B & c & c & B & & B & c & c & B & c & c & B & 1 \\
\hline & $\overline{\bar{a}}$ & $\bar{a}$ & 䓃 & $\bar{E}$ & $\vec{F}$ & a & & $\bar{z}$ & & & 몀 & & & & & & & है & 폄 & E & F & a & \\
\hline & & & $\begin{array}{ll}\hat{\hat{A}} & \hat{\hat{A}} \\
\hat{\hat{A}} & \hat{\hat{A}} \\
\hat{\hat{A}} & \hat{\hat{A}} \\
\hat{\hat{A}} & \hat{A}\end{array}$ & $\begin{array}{c}\mathrm{B} \\
\mathrm{B} \\
\mathrm{A} \\
\mathrm{B} \\
\mathrm{A} \\
\mathrm{A} \\
\mathrm{B} \\
\mathrm{A}\end{array}$ & $\begin{array}{l}\hat{\hat{A}} \\
\hat{\hat{A}} \\
\hat{\hat{A}} \\
\hat{\hat{A}} \\
\hat{\hat{A}}\end{array}$ & $\begin{array}{l}\mathrm{A} \\
\hat{A} \\
\hat{A} \\
\mathrm{~B} \\
\mathrm{~B} \\
\mathrm{~B} \\
\hat{\mathrm{A}} \\
\hat{\mathrm{C}} \\
\hat{A}\end{array}$ & $\begin{array}{l}\hat{A} \\
\hat{B} \\
\hat{B} \\
\hat{A}\end{array}$ & $\begin{array}{l}\mathrm{B} \\
\mathrm{B} \\
\mathrm{B} \\
\mathrm{C} \\
\mathrm{C} \\
\mathrm{B} \\
\mathrm{C} \\
\mathrm{C} \\
\mathrm{B} \\
\mathrm{C} \\
\mathrm{A} \\
\mathrm{A}\end{array}$ & $\begin{array}{c}\text { B } \\
\text { B } \\
\text { B } \\
\text { B } \\
\text { B }\end{array}$ & $\begin{array}{c}\mathrm{B} \\
\text { B } \\
\text { B } \\
\text { B } \\
\text { B } \\
\text { B } \\
B\end{array}$ & $\begin{array}{l}\hat{\hat{A}} \\
\hat{\hat{A}} \\
\hat{\hat{A}} \\
\hat{\hat{A}} \\
\hat{A}\end{array}$ & & $\begin{array}{l}8 \\
B \\
B \\
B \\
B \\
B \\
B\end{array}$ & & $\begin{array}{l}\mathrm{B} \\
\mathrm{B}\end{array}$ & $\begin{array}{c}\text { D. } \\
\text { B } \\
B\end{array}$ & & & $\begin{array}{l}c \\
c \\
c \\
c \\
c \\
B \\
c \\
c \\
B\end{array}$ & $\begin{array}{l}B \\
c \\
c \\
c \\
c \\
c \\
c \\
c \\
B \\
c \\
B \\
c\end{array}$ & $\begin{array}{l}c \\
c \\
c \\
c \\
c \\
c \\
c \\
c \\
c \\
c\end{array}$ & $\begin{array}{l}\text { B } \\
\text { B } \\
\text { B } \\
C \\
C \\
C \\
C \\
\text { B } \\
\text { C } \\
\text { B } \\
\text { S }\end{array}$ & \\
\hline
\end{tabular}

The final report is presented in Fig. 7. It shows the comparison of the domain level of students' competences in 
three moments: diagnostic, midterm and final. In some cases, it was observed that some students reached the expected domain level in the early stage of the project.

Based on the data shown in Table II, two condensed reports of quantitative results from de project are presented in Fig. 7 and 8.

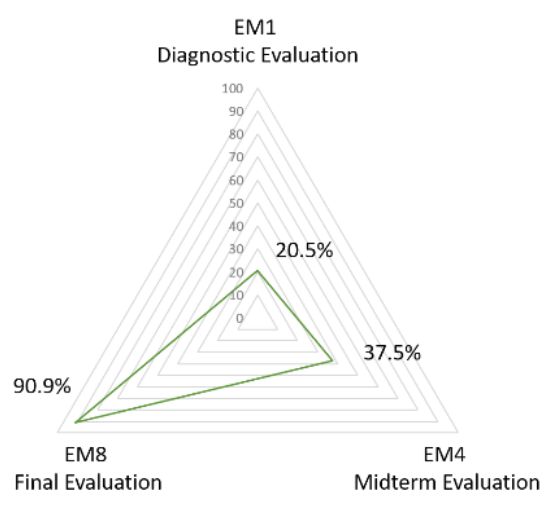

Fig. 7. Frequency occurrence of domain levels.

The Fig. 7 shows the effectiveness of the performance levels achieved for each sub-competence by the group of students at the time of diagnostic, midterm, and final evaluation, and it also shows the increase in the distribution of the expected domain level at each evaluation moment from $20.5 \%$ in the diagnostic evaluation to $90.8 \%$ in the final evaluation.

Using this information, we could conclude that the $90.8 \%$ of the students who participated in the project, developed the level of proficiency established for each of the 8 sub-competencies defined.

The Fig. 8 shows the percentage of students that reach the performance levels at the time of diagnostic, midterm, and final evaluation. It can be concluded that $98.9 \%$ of students developed level of proficiency $B$ or $C$ of the established sub-competences.

On the other hand, to solve the challenge posed in $D A \& C C v s B C$, two software applications were designed and implemented:

- SAPI, for the management and follow-up of treatment of patients with breast cancer and,

- SAVA, a tool for doctors to select treatment for patients.

Both applications were delivered to INCan authorities in December 2018. Due to the sensitive issue of confidential information handled in software applications, the applications are managed by the Technological Information Department of INCan. Both products are in testing period during 2019.

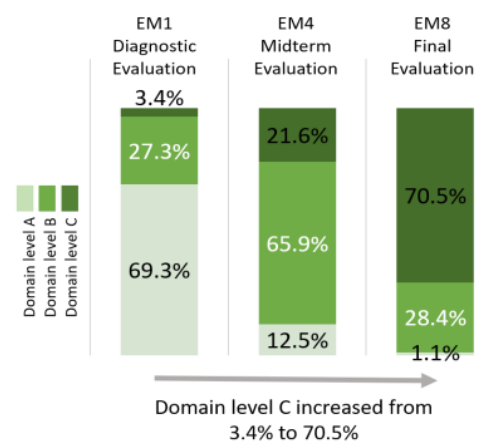

Fig. 8. Achievement of domain levels for established competences.

\section{CONClusions And Future WORK}

The characteristics and experience of the participating teachers, as well as the multidisciplinary team of 2 training partners, were key for building the learning environment.

The selection of the quantity and type of learning activities of the $D A \& C C v s B C$ enriched the design and achieved in the students of the Tec in Cuernavaca an experience with lasting learning. Through a survey, students evaluated their experience with a rating of 9.8 out of 10 .

It was observed that the choice of an inspiring problem situation as the basis for the challenge design, strengthened the students' commitment to build a solution to the challenge, while achieving that, the students reached the established domain levels for the defined competences.

The software products developed as a solution to the challenge were well received by the INCan and during 2019 the tools are in the testing period.

Currently, the second generation of students is starting to participate in the next stage of $D A \& C C v s B C$ in the academic period August - December 2019. This new team will continue with the improvement of SAPI and SAVA and will add new functionalities that will solve complementary challenges for INCan. It is intended to move forward with the vision of this project: "learning that helps".

\section{CONFLICT OF INTEREST}

The authors declare no conflict of interest.

\section{AUTHOR CONTRIBUTIONS}

Mónica Larre wrote the paper and managed communication with the training partners; Sergio Hernández evaluated and analyzed the competence development; Pedro Najera build the architecture of the research, Ramona Fuentes worked in the data analysis and proficiency levels; all authors had approved the final version.

\section{ACKNOWLEDGMENT}

The authors would like to acknowledge the financial and technical support of Writing Lab, TecLabs, Tecnologico de Monterrey, Mexico, in the production of this work.

Our recognition for Francisco Hurtado (Minsait by Indra), a key factor for the project realization. Also, a wide recognition for Dr. Bargalló, Director of the Department of Breast Tumors of INCAN who provided, always, full opening to the Tec team to carry out the project.

\section{REFERENCES}

[1] J. Jiménez. "Fue así como nació el tecnológico de monterrey," Tec Review, Septiembre 2017.

[2] D. Garza-Salazar, "Latin America university rankings 2019: Let's challenge students," The World University Rankings, 2019.

[3] R. Martínez, "Transformando la educación superior: El caso del modelo Tec21," presented at Congreso Internacional de Educación en Ingeniería, 2018.

[4] Y. Doppelt, "Implementation and assessment of project-based learning in a flexible environment," International Journal of Technology and Design Education, vol. 13, issue 3, pp. 255-272, 2003.

[5] D. H. Jonassen, J. Strobel, and C. B. Lee, "Everyday problem solving in engineering: lessons for engineering educators," Journal of Engineering Education, vol. 95 no. 2, pp. 139-151, 2006. 
[6] Indra, "Indra firma su segunda Cátedra de Tecnologías Accesibles en México con el Tecnológico de Monterrey en Cuernavaca," Indra en los medios, Febrero, 2018.

[7] Minsait-Indra, "La receta para que las empresas puedan convertir sus datos en una vía de negocio," El Confidencial, Diciembre 2019.

[8] A. Mohar et al., "Cáncer de mama en el Instituto Nacional de Cancerología. Experiencia del Seguro Popular 2007-2013,” Revista Mexicana de Mastología, vol. 5, no. 1, 2015.

[9] N. Reynoso-Noverón and J. A. Torres-Domínguez, "Epidemiology of cancer in México: Global burden and projections 2000-2020," Revista Latinoamericana de Medicina Conductual, vol. 8, no. 1, 2017.

[10] F. M. Knaul, J. Nigenda, R. Lozano, H. Arreola-Ornelas, A. Lagner, and J. Frenk, "Breast cancer in Mexico: An urgent priority," Salud Pública de México, vol. 51, pp. s335-44, January 2009.

[11] B. Özkan, R. Eskiyurt, and D. Öztaş, "Evaluation of the effectiveness of web-based intervention for patients with breast cancer," European Journal of Therapeutics.

[12] R. M. Clark and S. J. Dickerson, "A case study of post-workshop use of simpleactive learning in an introductory computing sequence," IEEE Trans. on Educ., vol. 61, no. 3, August 2018.

[13] E. Trepule, M. Tereseviciene, and A. Rutkiene, "Didactic approach of introducing technology enhanced learning (TEL) curriculum in highe education," in Proc. the 6th World Conference on Educational Sciences, June 2015.

[14] L. M. Hero and E. Lindfors, "Students' learning experience in a multidisciplinary innovation project," Education + Training, vol. 61, issue 4, pp. 500-522, 2019.

[15] P. Shekhar and M. Borrego, "After the workshop: A case study of postworkshop implementation of active learning in an electrica engineering course," IEEE Trans. Educ., vol. 60, no. 1, pp. 1-7, Feb. 2017.

$[16]$ Modelo
http://modelotec21.itesm.mx/files/folletomodelotec21.pdf

[17] C. Chen, T. Huang, T. Li, and C. Huang, "Personalized e-learning system with self-regulated learning assisted mechanisms for promoting learning performance," in Proc. Seventh IEEE International Conference on Advanced Learning Technologies (ICALT 2007), pp. 637-638, 2007

[18] J. Fluckiger et al., "Formative feedback: Involving students as partners in assessment to enhance learning," Journal College Teaching, vol. 58, no.4, pp. 136-140.

[19] H. S. Yüskel and N. Gündüz, "Formative and summative assessment in higher education: Opinions and practices of instructors," European Journal of Education Studies, vol. 3, issue 8, 2017.

[20] D. Carless, "Learning-oriented assessment: principles and practice," Journal Assessment \& Evaluation in Higher Education, vol. 21, issue 4 2006.

[21] A.W. Bates, "Competency-based learning," Teaching in a Digital Age, 2015, pp. 126-132.

[22] R. L. Colby, "Competency-based education a new architecture for K-12 schooling," Harvard Education Press, October 2017.

[23] D. Chatenier, J. M. Verstegen, H. A. Biemans, M. Mulder, and O. F. Omta, "Identification of competencies for professionals in open innovation teams," $R \& D$ Management, vol. 40 no. 3, pp. 271-280, 2010.

[24] L. M. Hero, E. Lindfors, and V. Taatila, "Individual innovation competence: A systematic review and future research agenda," Int Journal of Higher Education, vol. 6 no. 5, pp. 103-121, 2017.

[25] L. Liebenberg, and E. H. Mathews, "Integrating innovation skills in an introductory engineering design-build course," Int. Journal of Tech. and Design Education, vol. 22 no. 1, pp. 93-113, 2012.

[26] C. R. Brito, M. M. Ciampi, R. M. Vasconcelos, L. A. Amaral, H. D. Santos, and V. A. Barros, "Rethinking engineering education," 2017 IEEE Frontiers in Education Conference (FIE), Indianapolis, IN, 2017, pp. 1-5.x

[27] A. Bermudez, I. García-Varea, M. T. López et al., "Una definición precisa del concepto de Nivel de dominio de una competencia en el marco de aprendizaje basado en competencias," presented at Marco de la XVI Jornadas de Enseñanza de la Informática, Universidad de Castilla -La Mancha, 2011

[28] D. J. Nocil and D. Macfarlane-Dick, "Formative assessment and self-regulated learning: A model and seven principles of good feedback practice," Journal College Teaching, vol 58, issue 4, pp. 199-218. x

[29] Z. Baleni, "Formative assessment in higher education: Its pros and cons," Electronic Journal of e-Learning, vol. 13, no. 4, pp. 228-236, 2015.

[30] C. Canabal and L. Margalef, "La retroalimentación: La clave para una evaluación orientada al aprendizaje," Revista de Currículum y
Formación del Profesorado, ISSN; 1138-414X, vol. 21, no. 2, pp. 149-170, 2017.

[31] S. Donaire, B. García, and S. Oliver, "e-Portfolio: A tool to assess university students' skills," in Proc. 9th International Conference on Information Technology Based Higher Education and Training, 2010, pp.114 - 124.

[32] J. Beishuizen, P. Van-Boxel, P. Banyard, A. Twiner, H. Vermeij, and J. Underwood, "The introduction of portfolios in higher education: A comparative study in the UK and the Netherlands," European Journal of Education, 2006, vol. 41, no. 3/4.

[33] J. Fluckiger, Y. Tixier, V. R. Pasco, and K. Danielson, "Formative feedback: Involving students as partners in assessment to enhance learning," Journal of College Teaching, vol. 58, issue 4, pp. 136-140, Sep. 2010

[34] W. Bates, "Teaching in a digital age," Creative Commons Attribution NonCommercial.

[35] J. K. Huggins, "Engaging computer science students through cooperative education," ACM SIGCSE Bulletin, vol. 41, no. 4, Dec 2009.

[36] K. Lockwood and R. Esselstein, "The inverted classroom and the CS curriculum," in Proc. the 44th ACM Technical Symposium on Computer Science Education, pp. 113-118.

[37] M. J. Lage, G. J. Platt, and M. Treglia, "Inverting the classroom: A gateway to creating an inclusive learning environment," The Journal of Economic Education, vol. 31, no. 1, pp. 30-43, Jan. 2000

[38] G. C. Gannod, J. E. Burge, and M. T. Helmick, "Using the inverted classroom to teach software engineering," ACM/IEEE 30th International Conference on Software Engineering, 2008, pp 777-786.

[39] M. Maher, C. Latulipe, L. Richter, H. Lipford, and A. Rorrer, "Flipped classroom strategies for CS education," in Proc. the 46th ACM Technical Symposium on Computer Science Education, pp. 218-223, 2015.

[40] M. Eady and L. Lockyer, Tools for Learning: Technology and Teaching Strategies, Cambridge University Press, 2013

[41] S. Freeman et al., "Active learning increases student performance in science, engineering, and mathematics," in Proc. Nat. Acad. Sci., USA vol. 111, no. 23, pp. 1-6, Jun. 2014.

[42] L. Gleason et al., "An active-learning strategies primer for achieving ability-based educational outcomes," Amer. J. Pharmaceut. Educ., vol 75, no. 9, pp. 1-12, Nov. 2011.

[43] W. O'Brien, L. Soibelman, and G. Elvin, "Collaborative design processes: an active- and reflective-learning course in multidisciplinary collaboration," Journal of Construction Education, 2003, vol. 8, no. 2 , pp. 78-93.

[44] K. Kirchner and L. Razmerita, "Collaborative learning in the cloud: A cross-cultural perspective of collaboration," in Proc. the 26th ACM Conference on Hypertext \& Social Media, pp. 333-336.

[45] C. Chen, T. Huang, T. Li, and C. Huang, "Personalized e-learning system with self-regulated learning assisted mechanisms for promoting learning performance," in Proc. Seventh IEEE International conference on Advanced Learning Technologies (ICALT 2007), Niigata, 2007, pp. 637-638

[46] Self-regulated Learning in Technology-Enhanced Learning Environments: Studies in European Higher Education, Sep. - Dec. 2006, pp. 491-508

[47] P. J. Muñoz-Merino, J. A. Ruipérez-Valiente, C. Delgado, M. A. Auger, S. Briz, V. De-Castro, and S. N. Santalla, "Flipping the classroom to improve learning with MOOCs technology," Computer Applications in Engineering Education, vol. 25, no. 1, pp. 15-25, Jan. 2017.

[48] M. Dark and J. Mirkovic, "Evaluation theory and practice applied to cybersecurity education," IEEE Security \& Privacy, vol. 13, no. 2, pp 75-80, Mar.-Apr. 2015

Copyright (C) 2020 by the authors. This is an open access article distributed under the Creative Commons Attribution License which permits unrestricted use, distribution, and reproduction in any medium, provided the original work is properly cited (CC BY 4.0).

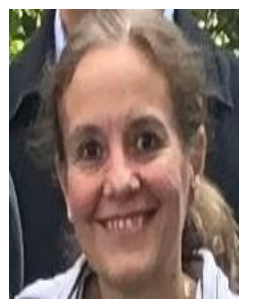

Mónica Larre Bolaños Cacho was born in Cuernavaca Morelos Mexico in 1965. She received the B.S., M.S. and Ph.D in computer science from the Monterrey Tech in 1986, 1989 and 2003 respectively. From 1986 to 1989 , she was a research assistant with the Institute of Electrical Research in Mexico. From 2003 to 2017, she was Academic Advisor, Academic Department and Academic Division Head, and since 2017 she has been a full Professor with the Computer 
Science Department at the Monterrey Tech. Her research interests include Educational Innovation, Programming Languages, Machine Learning and Databases Design. She is a member of the ACM and the IEEE communities.

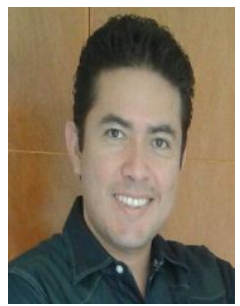

Sergio Francisco Hernández Alamilla was born in Martínez de la Torre, Veracruz, Mexico. He received the M.S. in computational sciences with a specialty in Artificial Intelligence from the Tecnológico de Monterrey and the title of master in animation and digital art from the Polytechnic University of Cataluña. He has experience as a leader in national projects for the pharmaceutical and multimedia industries and has published in international congresses. In 2016 he published the electronic book: "Fundamentals of programming: a practical approach". Currently he has the Unity Certified Developer professional certification and currently serves as Academic Advisor of Computer Technology Engineering at the Tecnológico de Monterrey Campus Cuernavaca.

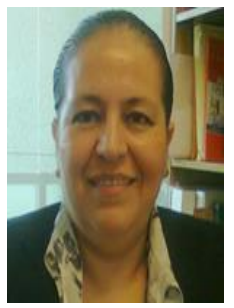

Ramona Fuentes-Valdéz was born in Mexicali, Baja California, Mexico. She received her master's degree in computer science with a specialization in digital systems from the Tecnologico de Monterrey in 1995. She is a professor of various subjects in the area of mathematics and information technology at Tecnologico de Monterrey, Cuernavaca, Mexico. She has published in international congresses, and the electronic book: "Logic Automatisms: Programmable and Reconfigurable" (2012) and a chapter of a book in 2018, about "Student behavior in the use of electronic media: digital citizenship". Her main research lines are around Information Technology, numerical methods, augmented reality, emerging technologies and education. Prof. Fuentes is an ACM member and has been honored as "Inspiring Professor" in 2017 at Tecnologico de Monterrey, Cuernavaca, Mexico, also she has been recognized with awards for teaching excellence in 2015 and 2009.

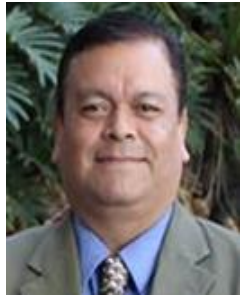

Pedro Nájera-García was born in Cuernavaca, Morelos, Mexico. He graduated with honours as an engineer in electronic systems by Tecnológico de Monterrey Campus Morelos, and also as a master's degree in computer science with a specialization in digital systems and control. He participated in the Electronics Department of the Electrical Research Institute and worked as a Senior Test Engineer in the area of automotive electronics at the company Temic (Telefunken Microelectronics) in the city of Cuautla and at the Temic Ingolstadt headquarters in Germany. Since August 1998 he has been a lecturer at the Department of Electronics in the Division of Engineering and Sciences of the Monterrey Tec Campus Cuernavaca and since 2001 has collaborated as a professor of electronics and Mechatronics in the Division of Professional. He has published in international congresses, and two electronic book: "Logic Automatisms: Programmable and Reconfigurable" (2012) and "The essentials of instrumentation in mechatronics". His main interest research areas are in the fields of Electronics and Mechatronics, FPGAs, Technological Entrepreneurship, Education and Poetry. Prof. Najera is an ACM member and has been honored as "Inspiring Professor" in 2016 at Tecnologico de Monterrey, Cuernavaca, Mexico, also he has been recognized with awards for teaching excellence in 2015 and 2009. 